\title{
Y-Specific DNA polymorphisms of the YAP element and the locus DYS19 in the Korean population
}

\begin{abstract}
The Y Alu polymorphic (YAP) element (DYS287) and the Y-linked tetranucleotide microsatellite locus DYS19 were examined in samples from a total of 455 unrelated males in the Korean population. The frequency of the $Y A P^{+}$allele was found to be $1.3 \%(6 / 455)$ in the Korean population. These results are consistent with previous reports that showed the YAP element to be absent in most Asian populations, with the exception of the high frequency of the $Y A P^{+}$allele in the Japanese population. All five common alleles at the DYS19 locus were identified in this study. The $\mathrm{C}$ allele was the most frequent (197/455), followed by the D (119/455), B (78/455), E (41/455), and A (20/455) alleles. Seven combination haplotypes (DYS287/ DYS19) were found, and the mean combination haplotype diversity in the Korean population appeared to be 0.71 . Based on results of these two loci, Japanese and Korean populations may share some common genetic structure that could reflect recent gene flow and some amount of admixture of Y chromosomes between these two populations.
\end{abstract}

Keyword Y Chromosome - DYS287 · DYS19 · Chinese · Japanese $\cdot$ Korean

\section{Introduction}

With the exception of the pseudoautosomal region, the human Y chromosome is haploid and paternally inherited without recombination. Consequently, Y haplotypes constructed with alleles at multiple polymorphic sites can be used for studies of paternal lineages and population history

W. Kim · D.J. Shin

Department of Biology, Dankook University, Cheonan 330-714,

Republic of Korea

Tel. +82-(0)417-550-3441; Fax +82-(0)417-550-3441

e-mail:wookkim@anseo.dankook.ac.kr

S.A. You · Y.J. Kim $(\bowtie)$

Department of Biology, Chungnam National University, Taejon 302-

764, Republic of Korea

Tel. +82-(0)42-821-5494; Fax +82-(0)42-822-9690

e-mail: kimangen@hanbat.chungnam.ac.kr in humans (Ngo et al. 1986; Hammer 1994; Spurdle et al. 1994a).

The presence or absence of the Y Alu polymorphic (YAP) insert (DYS287) has proved to be a useful marker for human population studies (Batzer and Deininger 1991; Perna et al. 1992; Hammer 1994, 1995; Hammer et al. 1997). The YAP insertion is likely to have originated only once, so it has the feature of a unique polymorphism (Hammer 1994). Significant differences in the frequencies of the YAP insertion were detected among worldwide populations (Hammer 1994; Hammer et al. 1997). The DYS19 microsatellite polymorphism is due to variation in the number of GATA repeats (Roewer et al. 1992; Santos et al. 1993, 1996b; Gomolka et al. 1994). It is known to be a useful tool for studying human population structure. There are at least nine different alleles, including five common alleles (A-E) that exhibit remarkable frequency differences in worldwide populations (Santos et al. 1993, 1996b; Gomolka et al. 1994; Hammer and Horai 1995). Therefore, these two genetic markers have been used to compare genetic similarities in different human ethnic groups. Here, we report results for the frequency of these two Y-linked specific markers in the Korean population.

\section{Subjects and methods}

We studied samples from a total of 455 unrelated Korean males for the detection of allelic variations at the loci $Y A P$ element (DYS287) and DYS19. DNA was extracted from buccal cells (Richards et al. 1993) from volunteer donors in Korea. The YAP insertion and DYS19 alleles were detected by polymerase chain reaction (PCR) amplification, using flanking primers described by Hammer and Horai (1995) and Roewer et al. (1992). The $Y A P^{+}(\sim 460 \mathrm{bp})$ or $Y A P^{-}$ fragment $(\sim 150 \mathrm{bp})$ of PCR products was electrophoresed in $2 \%$ agarose gel (Fig. 1). In the case of DYS19 alleles, the DNA fragments derived from PCR amplification were separated by using $10 \%$ polyacrylamide gel electrophoresis (PAGE) for $10 \mathrm{~h}$ at $100 \mathrm{~V}$. Following the PAGE, the frag- 


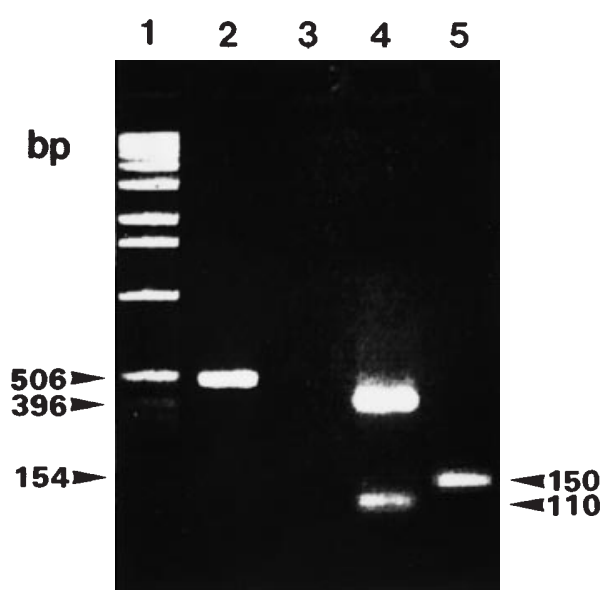

Fig. 1 Detection of insertion of $Y A P$ element in polymerase chain reaction $(\mathrm{PCR})$ products. Electrophoresis in a $2 \%$ agarose gel of restriction fragments of PCR product produced by digestion with TaqI. Lane 1, DNA size markers; lane 2, [YAP $\left.P^{+}\right] \mathrm{KK} 1$ sample; lane 3, female; lane 4, $\left[Y A P^{+}\right] \mathrm{KK} 1$ digested with TaqI; lane 5, YAP ${ }^{-}$control

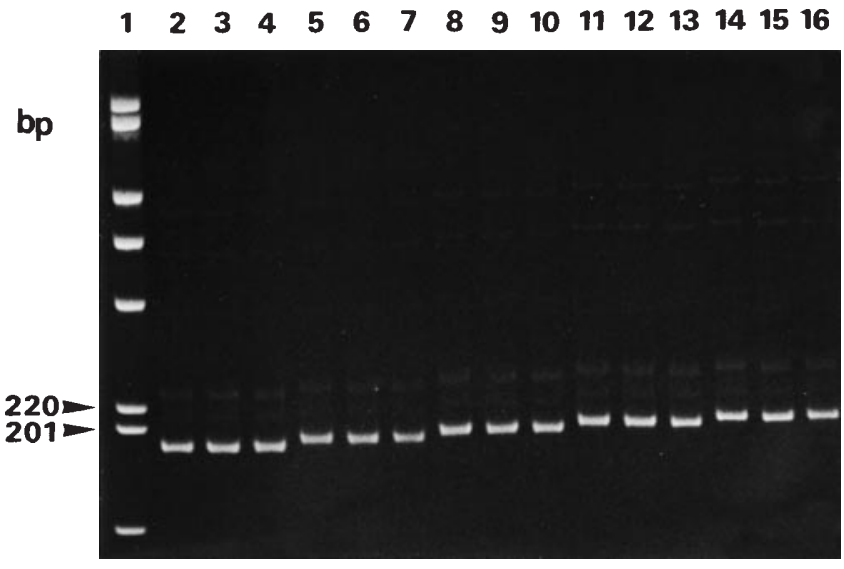

Fig. 2 Polyacrylamide gel electrophoresis of PCR products amplified with specific flanking primers of DYS19. Fifteen individuals displaying different allelic classes at the DYS19 locus in increasing order of size. Lane 1, DNA size markers; lanes 2-4, A (186 bp); lanes 5-7, B (190 bp); lanes 8-10, C (194bp); lanes 11-13, D (198bp); lanes 14-16, E (202 bp)
Fig. 3 Nei's genetic distance (Nei 1972) for the DYS19 locus in several Asian populations. Nei's standard genetic distance (D) in the table body was based on allele frequency of DYS19

\begin{tabular}{lcccccc}
\hline Population & $(1)$ & $(2)$ & $(3)$ & $(4)$ & $(5)$ & $(6)$ \\
\hline (1) Chinese & & & & & & \\
(2) Indians & 0.0159 & & & & & \\
(3) Japanese & 0.1550 & 0.2265 & & & \\
(4) Koreans & 0.0291 & 0.0693 & 0.0478 & & \\
(5) Mongolians & 0.0116 & 0.0237 & 0.2181 & 0.0603 & \\
(6) Tibetans & 0.1147 & 0.1153 & 0.1273 & 0.0854 & 0.1850 \\
\hline
\end{tabular}

ments were visualized using a simple ethidium bromide staining and ultraviolet light (Fig. 2).

The mean haplotype (gene) diversity was calculated for each group as $h=n\left(1-\Sigma \mathrm{x}_{i}^{2}\right) /(n-1)$, where $n$ represents the number of chromosomes sampled and $\mathrm{x}_{i}$ is the frequency of the $i$ th haplotype (Nei 1987). The PHYLIP Package (Felsenstein 1993) was used to compute genetic distances (Nei 1972) for use in distance matrix programs based on Y chromosome haplotype frequencies.

\section{Results}

Polymorphisms at the loci YAP element and DYS19. The frequencies of the YAP element and DYS19 alleles in this study are given, with the results of previous surveys, in Table 1 . The frequency of the $Y A P$ element insertion in the 455 Korean males was $1.3 \%(6 / 455)$. This result for the Korean population is consistent with previous reports that showed the YAP element to be absent in most Asian and Oceanic populations, with the exception of the highly polymorphic Japanese and Tibetans (Hammer 1994; Spurdle et al. 1994b; Hammer and Horai 1995; Hammer et al. 1997). The six $Y A P^{+}$chromosomes detected in this study were associated with long adenine residues (41 bp-50 bp) at the $3^{\prime}$ end of the Alu sequence (poly(A) tail) (data not shown). These chromosomes probably belong to haplotype 3 , which is frequently found in the Japanese population (Hammer 1995; Hammer et al. 1997).

All five common alleles (A-E) at the DYS19 locus were identified in the Korean population (Table 1). The $\mathrm{C}$ allele was the most frequent (197/455), followed by the D (119/ 455), B (78/455), E (41/455), and A (20/455) alleles. The predominance of the $\mathrm{C}$ allele in this study is similar to that in previous reports from other surveys of Asian, Australian aboriginal people, and indigenous African populations (Gomolka et al. 1994; Muller et al. 1994; Hammer and Horai 1995; Hammer et al. 1997). Nei's genetic distances, based on the frequencies for DYS19 alleles (Table 1), show that Koreans appeared to have the closest genetic relationship with Chinese (Fig. 3). The Japanese population is more similar to Koreans than to several other Asian populations.

A total of seven haplotypes were found with respect to the YAP/DYS19 combination in the Korean sample (Table 2 ). The mean combination haplotype diversity was 0.71 . In this survey, the haplotype $\mathrm{H} 3(-/ \mathrm{C})$ had the most common frequency $(42.9 \%)$. Among the seven YAP/DYS19 combination haplotypes, $Y A P^{-}$chromosomes were associated with all of five DYS19 alleles, while the $Y A P^{+}$allele was 
Table 1 Allele frequencies of two Y-chromosome specific loci in several Asian populations

\begin{tabular}{|c|c|c|c|c|c|c|c|c|c|}
\hline \multirow[b]{2}{*}{ Population $(n)$} & \multicolumn{2}{|c|}{ No. (\%) of $Y A P$ allele } & \multicolumn{7}{|c|}{ No. (\%) of DYS19 allele } \\
\hline & + & - & $\mathrm{Z}$ & A & $\mathrm{B}$ & $\mathrm{C}$ & $\mathrm{D}$ & $\mathrm{E}$ & $\mathrm{F}$ \\
\hline Chinese $(76)^{*, a}$ & $1(1.3)$ & 75 (98.7) & $1(1.3)$ & $3(3.9)$ & $21(27.6)$ & $29(38.2)$ & $19(25.0)$ & $3(3.9)$ & 0 \\
\hline Indians $(43)^{6}$ & 0 & $43(100.0)$ & 0 & $1(2.3)$ & $15(34.9)$ & $17(39.5)$ & $8(18.6)$ & $2(4.7)$ & 0 \\
\hline Japanese $(132)_{d}^{c}$ & $55(41.7)$ & $77(58.3)$ & 0 & $10(7.6)$ & $4(3.0)$ & $63(47.7)$ & $32(24.2)$ & $22(16.7)$ & $1(0.8)$ \\
\hline Koreans $(455)$ & $6(1.3)$ & $449(98.7)$ & 0 & $20(4.4)$ & $78(17.1)$ & $197(43.3)$ & $119(26.2)$ & $41(9.0)$ & 0 \\
\hline Mongolians $(46)^{\mathrm{e}}$ & $1(2.2)$ & $45(97.8)$ & 0 & $1(2.2)$ & $14(30.4)$ & $15(32.6)$ & $12(26.1)$ & $2(4.3)$ & $2(4.3)$ \\
\hline Tibetans $(30)^{\mathrm{b}}$ & $14(46.7)$ & $17(53.3)$ & 0 & 0 & $7(23.3)$ & $20(66.7)$ & $3(10.0)$ & 0 & 0 \\
\hline
\end{tabular}

${ }^{a}$ Hammer et al. (1997); ${ }^{b}$ Hammer and Karafet (unpublished data); ${ }^{\mathrm{c}}$ Hammer and Horai $(1995) ;{ }^{\mathrm{d}}$ Present study; ${ }^{\mathrm{e}}$ Santos et al. (1996a)

*Most are Taiwanese of Chinese ancestry (Horai et al. 1987; Hammer and Horai 1995)

Table 2 Comparison of frequencies for the YAP/DYS19

combination haplotype in the Korean population

\begin{tabular}{llc}
\hline $\begin{array}{l}\text { Haplotype } \\
\text { number }\end{array}$ & $\begin{array}{l}\text { Combination haplotype } \\
(Y A P / D Y S 19)\end{array}$ & $\begin{array}{l}\text { No. }(\%) \\
(n=455)\end{array}$ \\
\hline H1 & $-/ \mathrm{A}$ & $20(4.4)$ \\
H2 & - B & $78(17.1)$ \\
H3 & $-/ \mathrm{C}$ & $195(42.9)$ \\
H4 & - D & $115(25.3)$ \\
H5 & $-/ \mathrm{E}$ & $41(9.0)$ \\
H6 & $+/ \mathrm{C}$ & $2(0.4)$ \\
H7 & $+/ D$ & $4(0.9)$ \\
\hline
\end{tabular}

Mean haplotype diversity values appeared to be 0.71 in the Korean population

associated only with the C and D alleles of DYS19 (Table 2). This result is consistent with a previous report that, in East Asia, the $\mathrm{YAP}^{+}$chromosome (haplotype 3 ) is mainly associated with the C and D alleles of DYS19 and was never found with the DYS19 B allele (Hammer et al. 1997).

\section{Discussion}

The genetic structure of the Korean population. The Korean population appears to have an extremely low frequency of the $Y_{A P^{+}}$allele $(6 / 455)$ (Table 1$)$. This result is consistent with earlier reports showing that most East Asian populations have very low frequencies of the $Y A P^{+}$allele (less than $2 \%)$. The notable exception to this pattern was the finding of high frequencies of the $Y A P^{+}$allele in Japan $(41.7 \%)$ and Tibet (46.7\%) (Hammer and Horai 1995; Hammer et al. 1997). On the other hand, the DYS19 data presented here indicate that the Korean population is more similar to the Chinese. The Japanese population appears to have a closer genetic relationship to Koreans than to the other surveyed Asian populations (Fig. 3). Most authors generally agree that Koreans are considered as a North Asian group (Nei and Roychoudhury 1993; Cavalli-Sforza et al. 1994). Earlier reports of the frequencies of the $Y A P /$ DYS19 combination haplotypes (Table 1) suggest that Japanese and Tibetan populations shared a common ancestral population. These results may reflect the "out of northeast-Asia hypothesis" of the origin of Japanese populations (Hammer and Horai 1995; Nei 1995).
The YAP/DYS19 combination haplotype diversity in the Korean population $(h=0.71)$ was found to be lower than that in other Asian populations. A global survey has shown that sub-Saharan Africans have the highest diversity (0.878) of this mean combination haplotype, followed by Asians (0.779), Europeans (0.736), and indigenous Australasians (0.718) (Hammer et al. 1997). The low diversity level detected in our Korean sample may be due to the homogenizing influence of migrations from northeast Asia (Nei and Roychoudhury 1993; Cavalli-Sforza et al. 1994). Indeed, the high Japanese diversity levels in Asians (0.835) have been explained as resulting from a combination of an ancient population (Jomon people) subject to a more recent admixture (Yayoi people) (Hammer and Horai 1995; Hammer et al. 1997).

Based on the results for these two loci, it seems that Korean and Japanese populations may share some common genetic structure that is rare or not present in the other groups. Earlier surveys of $D X Y S 5 Y(47 \mathrm{z})$ polymorphisms in Africa, East Asia, and Europe suggest that the Y2 allele is restricted to Korea and Japan (Nakagome et al. 1992; Mathias et al. 1994). A similar overall pattern was detected in a much larger sample of Koreans $(n=480$, Y2 $=4.6 \%$, W. Kim and D.J. Shin, unpublished data). This similarity may be because there has been some admixture between these two populations. This is also consistent with the hypothesis that the Y2 allele tracks male lineages that originated in Korea and migrated to Japan (Hammer and Horai 1995). Hammer and Horai (1995) reported that there were high frequencies of the $Y A P^{+}$haplotype in Hokkaido and in Okinawa, with lower frequencies in southwestern Japan, the region closest to the Korean peninsula. There is also evidence for a migration of Yayoi people from the Korean peninsula to Japan about 2300 years ago (Chard 1974). An extremely low frequency of $Y A P^{+}$alleles $(1.3 \%)$ in the Korean population provides additional evidence to support this hypothesis.

Based on the results shown here, the $6 Y A P^{+}$chromosomes detected in our survey had the long poly (A) tail (41$50 \mathrm{dA}$-nucleotides) at the $3^{\prime}$ end of the Alu sequence. This is consistent with their belonging to $Y A P$ haplotype 3, which is frequently found in Japanese populations (Hammer 1995; Hammer et al. 1997). This result could reflect a recent gene flow from Japan to Korea. Therefore, we suggest that the rate of admixture for $Y A P^{+}$chromosomes 
from Japan to Korea seems to be lower than that of the apparently large infusion of $Y A P^{-}$chromosomes with the Yayoi migration, starting 2300 years ago, from Korea to Japan.

Acknowledgments We thank Dr.M.F. Hammer for help and advice during the course of this work. This study was supported by the Basic Science Research Institute Program (BSRI-96- No. 4440) of the Ministry of Education, Republic of Korea.

\section{References}

Batzer MA, Deininger PL (1991) A human-specific subfamily of Alu sequences. Genomics 9: 481-487

Cavalli-Sforza LL, Menozzi P, Piazza A (1994) The history and geography of human genes. Princeton University Press, Princeton

Chard C (1974) Northeast Asia in prehistory. University of Wisconsin Press, Madison

Felsenstein J (1993) PHYLIP. Phylogeny Inference Package, Version 3.5p. Joseph Felsenstein and the University of Washington, Seattle

Gomolka M, Hundrieser J, Nurnberg P, Roewer L, Epplen JT, Epplen C (1994) Selected di- and tetranucleotide microsatellites from chromosomes 7, 12, 14, and Y in various Eurasian populations. Hum Genet 93: 592-596

Hammer MF (1994) A recent insertion of an Alu element on the Y chromosome is a useful marker for human population studies. Mol Biol Evol 11: 749-761

Hammer MF (1995) A recent common ancestry for human Y chromosomes. Nature 378: 376-378

Hammer MF, Horai S (1995) Y chromosomal DNA variation and the peopling of Japan. Am J Hum Genet 56: 951-962

Hammer MF, Spurdle AB, Karafet T, Bonner MR, Wood ET, Novelletto A, Malaspina P, Mitchell RJ, Horai S, Jenkins T, Zegura SL (1997) The geographic distribution of human Y chromosome variation. Genetics 145: 787-805

Horai S, Gojobori T, Matsunaga E (1987) Evolutionary implications of mitochondrial DNA polymorphism in human populations. In: Vogel F, Sperlings K (eds) Human genetics: Proceedings of the 7th international congress. Springer, Heidelberg, pp 171-181

Mathias N, Bayes M, Tyler-Smith C (1994) Highly informative compound haplotypes for the human Y chromosome. Hum Mol Genet 3: $115-123$
Muller S, Gomolka M, Walter H (1994) The Y-specific SSLP of the locus DYS19 in four different European samples. Hum Hered 44: 298-300

Nakagome Y, Young SR, Akane A, Numabe H, Jin DK, Yamori Y, Seki S, Tamura T, Nagafuchi S, Shiono H, Nakahori Y (1992) A Yassociated allele may be characteristic of certain ethnic groups in Asia. Ann Hum Genet 56: 311-314

Nei M (1972) Genetic distance between populations. Am Nat 106: $283-$ 292

Nei M (1987) Molecular evolutionary genetics. Columbia University Press, New York

Nei M (1995) The origins of human populations. Genetics, linguistic and archeological data. In: Brenner S, Hanihara K (eds) The origin and past of modern humans as viewed from DNA. World Scientific, Singapore, pp 71-91

Nei M, Roychoudhury AK (1993) Evolutionary relationships of human populations on a global scale. Mol Biol Evol 10: 927-943

Ngo KY, Vergnaud G, Johnsson C, Lucotte G, Weissenbach J (1986) A DNA probe detecting multiple haplotypes of the human Y chromosome. Am J Hum Genet 38: 407-418

Perna NT, Batzer MA, Deininger PL, Stoneking M (1992) Alu insertion polymorphism: A new type of marker for human population studies. Hum Biol 64: 641-648

Richards B, Skoletsky J, Shuber AP, Balfour R, Stern RC, Dorkin HL, Parad RB, Witt D, Klinger KW (1993) Multiplex PCR amplification from the CFTR gene using DNA prepared from buccal brushes/ swabs. Hum Mol Genet 2: 159-163

Roewer L, Arnemann J, Spurr NK, Grzeschik KH, Epplen JT (1992) Simple repeat sequences on the human Y chromosome are equally polymorphic as their autosomal counterparts. Hum Genet 89: 389394

Santos FR, Bianchi NO, Pena SDJ (1996a) Worldwide distribution of human Y-chromosome haplotype. Genome Res 6: 601-611

Santos FR, Gerelsaikhan T, Munkhtuja B, Oyunsuren T, Epplen JT, Pena SDJ (1996b) Geographic differences in the allele frequencies of the human Y-linked tetranucleotide polymorphism DYS19. Hum Genet 97: 309-313

Santos FR, Pena SDJ, Epplen JT (1993) Genetic and population study of a Y-linked tetranucleotide repeat DNA polymorphism with a simple non-isotopic technique. Hum Genet 90: 655-656

Spurdle AB, Hammer MF, Jenkins T (1994a) The Y Alu polymorphism in southern African populations and its relationship to other Y-specific polymorphisms. Am J Hum Genet 54: 319-330

Spurdle AB, Woodfield DG, Hammer MF, Jenkins T (1994b) The genetic affinity of Polynesians: Evidence from Y chromosome polymorphism. Ann Hum Genet 58: 251-263 